\title{
Thrombocytopenia as a surrogate marker of hepatosplenic schistosomiasis in endemic areas for Schistosomiasis mansoni
}

\author{
Sandra Costa Drummond ${ }^{[1]}$, Pedro Nunes Pereira ${ }^{[2]}$, Alba Otoni ${ }^{[1]}$, Bruna Assis Chaves ${ }^{[1]}$, \\ Carlos Maurício Antunes ${ }^{[3]}$ and José Roberto Lambertucci ${ }^{[1]}$
}

[1]. Departamento de Infectologia e Medicina Tropical, Universidade Federal de Minas Gerais, Belo Horizonte, MG. [2]. Serviço de Radiologia, Faculdade de Medicina, Universidade Federal de Minas Gerais, Belo Horizonte, MG. [3]. Unidade de Epidemiologia, Santa Casa de Belo Horizonte, Belo Horizonte, MG.

\begin{abstract}
Introduction: This study aimed to evaluate whether a low platelet count is a good surrogate marker of hepatosplenic schistosomiasis (HSS) in a rural area of Brazil. A small district in southeastern Brazil, with a population of 1,543 individuals and a 23\% prevalence of schistosomiasis, was selected for this investigation. Methods: In July 2012, 384 volunteers were subjected to clinical, ultrasonography (US), and laboratory examinations, including stool sample analysis. The HSS patients were classified into four groups: Group 1 consisted of patients with a spleen $>13 \mathrm{~cm}$ and liver fibrosis; Group 2 consisted of patients with a palpable spleen and spleen $>13 \mathrm{~cm}$ measured by US; Group 3 consisted of patients with a spleen $>13 \mathrm{~cm}$ measured by US; and Group 4 consisted of patients with a palpable spleen. Results: Eight patients were in Group 1 (2.1\%), twenty-one were in Group 2 (5.5\%), eight were in Group 3 (2.1\%), and eighteen were in Group 4 (4.7\%). A significant difference in the mean platelet counts was observed between the patients with and without HSS $(p<0.01)$. Based on the receiver operating characteristic (ROC) curve (platelet count $<143,000 / \mathrm{mm}^{3}$ ), the sensitivity was greater than $92 \%$ in all groups, and the specificity varied from 44.4\% to $75 \%$. Conclusions: We concluded that in endemic areas, thrombocytopenia demonstrates good sensitivity for detecting HSS and may be used as a screening tool to identify patients with HSS.
\end{abstract}

Keywords: Thrombocytopenia. Platelets. Hepatosplenic schistosomiasis. Pseudo-thrombocytopenia. Schistosomiasis mansoni.

\section{INTRODUCTION}

It has been estimated that 240 million people worldwide are infected with schistosomiasis, with an additional 700 million at risk of infection. Currently, 2 to 6 million individuals are considered to be infected in Brazil ${ }^{1}$.

Most of the infected individuals are asymptomatic, but in 5\% to $10 \%$ of infected individuals, liver periportal fibrosis results in severe disease consisting of portal hypertension, splenomegaly, esophageal varices, and recurrent hematemesis ${ }^{2}$. Pathologically, dense bands of fibrosis around the portal tracts are typical of schistosomiasis ${ }^{3}$.

Schistosomal periportal fibrosis is usually assessed using imaging methods, and abdominal ultrasonography (US) has become the imaging technique of choice $^{4-8}$. However, the identification of other non-invasive, inexpensive, and simple routine laboratory tests as surrogate markers is of interest.

Address to: Dr. José Roberto Lambertucci. Depto ${ }^{\circ}$ de Infectologia e Medicina Tropical/UFMG. Av. Alfredo Balena 190, 30130-100 Belo Horizonte, MG, Brasil.

Phone: 5531 3337-7781

e-mail: lamber@uai.com.br

Received 30 January 2014

Accepted 11 April 2014
Such markers would facilitate the selection of patients with hepatosplenic schistosomiasis (HSS) in rural areas for further clinical and laboratory evaluations.

In the hepatosplenic form of schistosomiasis, portal hypertension is the most evident clinical complication, and splenomegaly with platelet sequestration in the spleen is the most accepted explanation for thrombocytopenia ${ }^{9,10}$.

However, thrombocytopenia has been shown to be a good marker of HSS in patients admitted to Brazilian hospitals. A group of Brazilian authors showed that low blood platelet counts were associated with portal hypertension, and others also found an association between low platelet counts and the intensity of liver fibrosis ${ }^{11,12}$.

This study aimed to determine whether low platelet counts in the blood can be used as a screening tool to identify patients with HSS in an area endemic for Schistosomiasis mansoni in Brazil.

\section{METHODS}

\section{Patients}

This was a cross-sectional, analytical study. Topázio, a small district in Teófilo Otoni, State of Minas Gerais, Brazil, with a population of 1,543 individuals and a $23 \%$ prevalence of schistosomiasis, was selected for this investigation. A total of 400 volunteers with ages ranging from 16 to 97 years 
(median=41) were enrolled in the study after signing informed consent forms. During one week in July 2008, a local health agent invited all volunteers to be examined in a local outpatient clinic; three individuals did not respond to our invitation, and $13(3.3 \%)$ were excluded because they did not complete the examinations. Therefore, a total of 384 volunteers were ultimately included in the study.

\section{Clinical examination}

The 384 participants were subjected to anamnesis and physical examination by one of the authors (JRL). Particular attention was given to the abdominal examination; specifically, the right hepatic lobe was examined along the anterior axillary line, and the left hepatic lobe was examined along a line passing through the xiphoid process. The spleen was palpated and measured under the left costal margin with the patient in the dorsal decubitus position during deep inspiration ${ }^{13-19}$.

\section{Ultrasound}

All participants were submitted to abdominal US using a portable Medison Sonoace 1500 system with a 3.5-MHz probe (Samsung, Korea) and examined according to the proposed protocol of the World Health Organization (WHO) for US assessment of schistosomiasis-related morbidity ${ }^{20}$. In this study, we used a spleen size cut-off point of $>13 \mathrm{~cm}$ (longitudinal diameter) because spleens tend to be more enlarged in HSS than in other diseases that evolve with splenomegaly, such as cirrhosis and mononucleosis-like syndromes ${ }^{21-26}$.

\section{Definition of hepatosplenic schistosomiasis}

HSS was classified into four groups: Group 1 consisted of patients with a spleen $>13 \mathrm{~cm}$ and liver periportal fibrosis, as confirmed by US; Group 2 consisted of patients with a palpable spleen and spleen $>13 \mathrm{~cm}$, as measured by US; Group 3 consisted of patients with a spleen $>13 \mathrm{~cm}$ using US; and Group 4 consisted of patients with a palpable spleen.

\section{Laboratory studies}

Stool samples from 1,543 individuals (2 slides each) were examined using the Kato-Katz technique. A 10-ml sample of blood was collected from a peripheral vein in a tube containing ethylenediamine tetraacetic acid (EDTA) as an anticoagulant, and a hemogram with platelet counts was performed (Sysmex, E 2100 D). Individuals positive for schistosomiasis were treated with a single oral dose of praziquantel $(50 \mathrm{mg} / \mathrm{kg} \text { body weight })^{27}$.

\section{Statistical analysis}

The questionnaire data were transferred to a databank using the EpiData 3.1 program (EpiData Association, Odense, Denmark) and analyzed using Statistical Package for Social Sciences (SPSS) 18.0 software (SPSS, IBM Company, Chicago, IL). Tables were constructed, and the percentages, median values, and mean values were calculated. Categorical variables were compared using the $\chi 2$ test; mean values were compared using Student's $t$-test or analysis of variance (ANOVA); and median values were compared using the Kruskal-Wallis test. Additionally, Spearman correlation analysis was performed for continuous variables, and receiver operating characteristic (ROC) curves were used to define the cut-off value of platelet counts to aid in identifying the best combination of sensitivity and specificity. The areas under the ROC curves were calculated to define the accuracy of the platelet counts in the identification of patients with HSS. Differences between the groups were evaluated using the MannWhitney test. Statistical significance was accepted at the 5\% level.

\section{Ethical considerations}

This study was approved by the Human Research Ethical Board at the Federal University of Minas Gerais School of Medicine.

\section{RESULTS}

The comprehensive flow chart shown in Figure 1 summarizes the results of the present study. Demographic data and physical examination findings in the 384 individuals of this study are presented in Table 1. Eight patients in the group with HSS and 136 in the group without HSS ( $\mathrm{p}=0.92)$ were male. Overall, the patients with HSS were older than the individuals without HSS $(\mathrm{p}<0.00)$.

The mean platelet counts in individuals with and without HSS were $152,952 \pm 66,341 / \mathrm{mm}^{3}$ and $237,275 \pm 84,345 / \mathrm{mm}^{3}$, respectively $(\mathrm{p}<0.01)$.

Using the ROC curve, we found that a platelet count $<143,000 / \mathrm{mm}^{3}$ yielded the highest sensitivity and specificity for each HSS definition (Figure 1).

In Table 2, the area under the ROC curves (AUC), confidence intervals (CIs), and sensitivity and specificity of the ROC curves for a platelet cut-off point of $<143,000 / \mathrm{mm}^{3}$ are presented for each definition of hepatosplenic schistosomiasis.

\section{DISCUSSION}

This report is the first fieldwork investigation demonstrating that thrombocytopenia can be used as a surrogate marker of HSS in areas highly endemic for schistosomiasis. Souza et al. ${ }^{11}$ showed that low blood platelet counts were related to portal hypertension in schistosomiasis. In addition, Lambertucci et al. ${ }^{12}$ also found that blood platelet counts less than $140,000 / \mathrm{mm}^{3}$ identified patients with HSS (a relationship was observed between the spleen size and liver periportal fibrosis grading). Both studies were performed in patients who were admitted to University Hospitals in large cities.

If the successful use of this simple and inexpensive marker for HSS in endemic areas is confirmed by others, then this marker would hasten the identification of morbidity in poor areas of the country. Patients selected based on a thrombocytopenia assessment would then have their diagnosis confirmed by other tests, such as US.

In the present study, the patients with HSS were found to be older than the individuals without HSS $(\mathrm{p}<0.00)$. A possible explanation for this observation is the initiation of a mass chemotherapy program for schistosomiasis in the late 1970s 


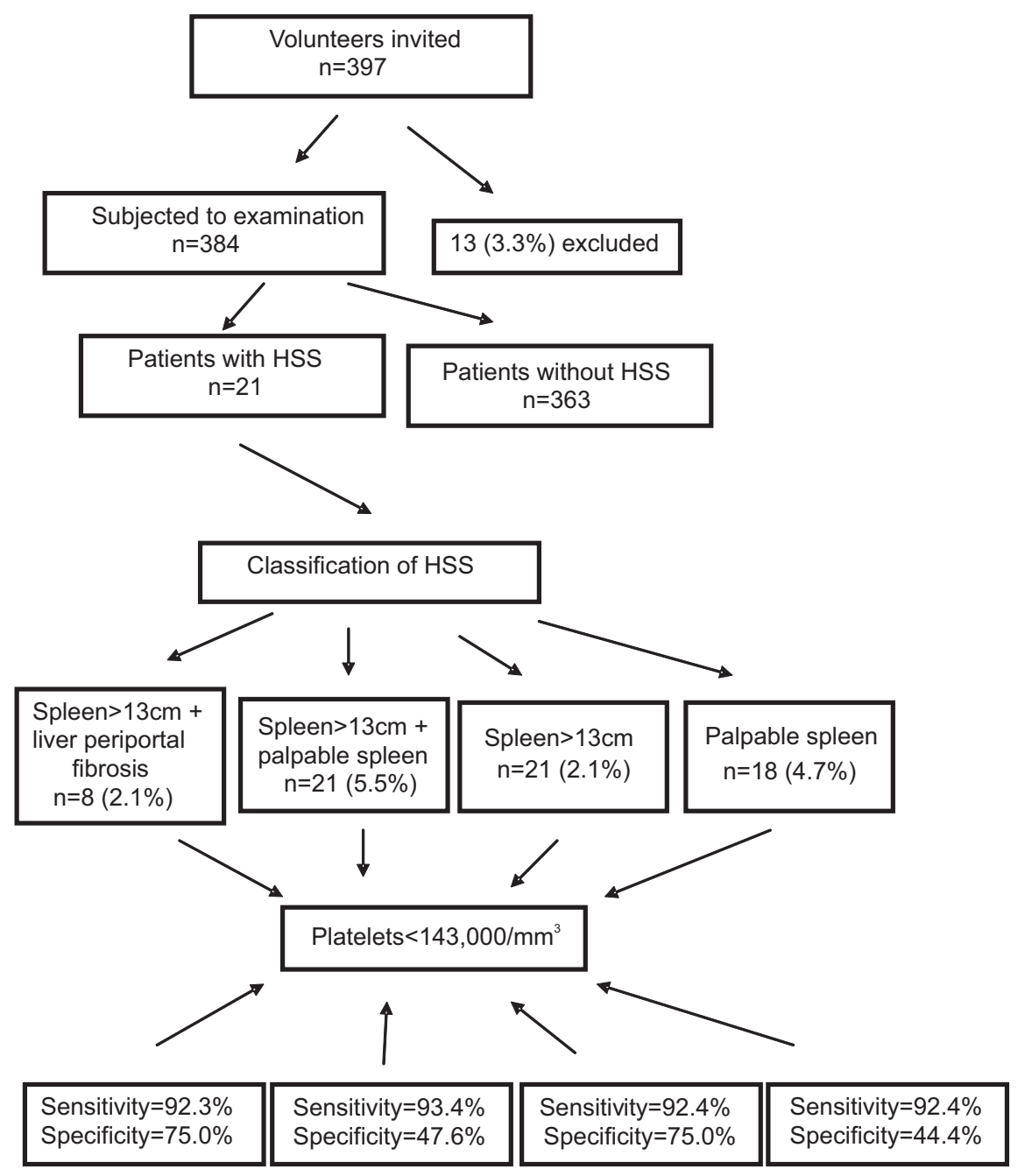

FIGURE 1 - Flow chart of the study. Patients with spleens $>13 \mathrm{~cm}$ and liver periportal fibrosis were evaluated using ultrasound. HSS: hepatosplenic schistosomiasis.

TABLE 1 - Demographic and physical examination data of 384 individuals with and without hepatosplenic schistosomiasis in the district of Teófilo Otoni, State of Minas Gerais, Brazil, who were examined during a week in July 2012.

\begin{tabular}{|c|c|c|c|}
\hline & $\begin{array}{l}\text { Patients with hepatosplenic } \\
\text { schistosomiasis }(n=21)\end{array}$ & $\begin{array}{l}\text { Individuals without hepatosplenic } \\
\text { schistosomiasis }(\mathrm{n}=363)\end{array}$ & \\
\hline Demographic and clinical data & Median (min-max) & Median (min-max) & $\mathrm{p}$ value \\
\hline Weight & $59(31-83)$ & $58(29-103)$ & 0.99 \\
\hline Height & $157(134-169)$ & $158(135-193)$ & 0.09 \\
\hline Systemic systolic blood pressure & $140(100-200)$ & $130(85-250)$ & 0.27 \\
\hline Systemic diastolic blood pressure & $88(60-120)$ & $80(50-140)$ & 0.49 \\
\hline
\end{tabular}


TABLE 2 - Areas under the ROC curves (AUCs), confidence intervals, and sensitivity and specificity of the ROC curves for a platelet cut-off point of $<143,000 / \mathrm{mm}^{3}$ for each definition of hepatosplenic schistosomiasis.

\begin{tabular}{|c|c|c|c|c|}
\hline & \#AUC & & Sensitivity & Specificity \\
\hline Definitions* & $(\%)$ & CI & $(\%)$ & $(\%)$ \\
\hline Group 1 & 92.3 & $85.0-99.5$ & 92.3 & 75.0 \\
\hline Group 2 & 77.2 & $65.5-88.8$ & 93.4 & 47.6 \\
\hline Group 3 & 92.2 & 85.0 - 99.4 & 92.4 & 75.0 \\
\hline Group 4 & 74.4 & $48.5-80.4$ & 93.0 & 44.4 \\
\hline
\end{tabular}

*Group 1: spleen $>13 \mathrm{~cm}+$ liver periportal fibrosis; Group 2: spleen $>13 \mathrm{~cm}+$ palpable spleen; Group 3: spleen $>13 \mathrm{~cm}$; Group 4: palpable spleen. \#AUC: Area under the ROC curve. ROC: receiver operating characteristic; CI: confidence interval.

in Brazil. As the program was directed especially toward school children, it can be seen that the mean age of patients with HSS has shifted to an older population (age-cohort effect).

The median platelet counts were significantly lower in individuals with HSS $(\mathrm{p}<0.01)$, and platelet counts $<143,000 / \mathrm{mm}^{3}$ identified patients with HSS with a sensitivity $>92 \%$. The prevalence of the disease was $23 \%$ in the study area. As expected, with a platelet count $<143,000 / \mathrm{mm}^{3}$, sensitivities and specificities for the diagnosis of HSS varied depending on the definition of HSS. Based on the HSS definition of a palpable spleen and a spleen $>13 \mathrm{~cm}$ measured by US, 21 individuals $(5.5 \%$ of the people enrolled in the study) had HSS, with a sensitivity of $93.4 \%$ and specificity of $47.6 \%$. Some individuals with enlarged spleens most likely had other diseases, which would explain the low specificity. In addition, errors that occur during abdominal palpation or US examination cannot be excluded. When the HSS definition consisted of a spleen $>13 \mathrm{~cm}$ that was associated with periportal fibrosis as confirmed by US, $8(2.1 \%)$ patients had HSS, with a sensitivity of $92.3 \%$ and specificity of $75 \%$. This definition appears to be more accurate because it includes the characteristic schistosomal liver periportal fibrosis.

A group of 20 individuals with periportal fibrosis confirmed by US but with normal spleens was identified in our study, and the platelet counts were normal in this group. Symmer's periportal fibrosis without splenomegaly has been reported previously $y^{2,13,28}$. This finding demonstrates the importance of enlarged spleens in schistosomal thrombocytopenia, and this condition has been referred to as the hepatic form of the disease. Knowing whether such patients have esophageal varices would be interesting. It is of interest to know whether these individuals bleed similarly to patients with HSS. Severe upper digestive bleeding in patients without esophageal varices but with duodenal varices has been reported ${ }^{29,30}$. An upper digestive endoscopy may partially address this issue in such patients. If this hypothesis is confirmed, this clinical form of schistosomiasis may be classified as hepatic with or without esophageal varices.
To confirm the field diagnosis, we brought 22 individuals with thrombocytopenia to our University Hospital in Belo Horizonte to undergo examination. Every week, two patients were admitted to the hospital for five days. During the first two weeks, we found one patient who presented a variable number of platelet counts: 35,000 , $27,000,93,000,37,000$, and zero. In addition, platelet clumping was observed in a peripheral blood smear. After changing the anticoagulant (EDTA to heparin), the platelet count increased to $160,000 / \mathrm{mm}^{3}$. The patient was diagnosed with pseudothrombocytopenia (an in vitro error) and was reallocated to the group with normal platelet counts. Pseudothrombocytopenia has been reported to occur in as many as $17 \%$ of patients who visit hematology units to seek a diagnosis for their thrombocytopenia ${ }^{31-36}$. We are planning a new study in rural areas of Brazil that are endemic for schistosomiasis to assess the frequency of pseudothrombocytopenia. Thrombocytopenia is a nuisance in the life of patients with HSS. Minor surgical, dental, and diagnostic procedures have been refused to these patients by misinformed healthcare professionals due to the possibility of bleeding because of low platelet counts. A percentage of such patients may have pseudothrombocytopenia, an artifact that can be easily avoided.

The major mechanisms associated with reduced platelet counts are the following: 1) decreased production (e.g., due to diseases or toxic drugs that affect the bone marrow); 2) increased destruction (caused by cytotoxic agents and other drugs, viral infections, and vitamin B12 or folic acid deficiency); 3) dilutional thrombocytopenia (caused by blood transfusions with packed red blood cells); 4) distributional thrombocytopenia (caused by splenomegaly); 5) increased platelet destruction [caused by autoimmune diseases, use of heparin, and diseases such as infectious mononucleosis, cytomegalovirus, and acquired immune deficiency syndrome (AIDS)]. Therefore, all these situations should be kept in mind and considered when analyzing thrombocytopenia in areas endemic for schistosomiasis.

We concluded that in areas endemic for schistosomiasis with a prevalence of $23 \%$, platelet counts $<143,000 / \mathrm{mm}^{3}$ identified HSS patients with good sensitivity and moderate specificity and can be used as a screening tool to identify severe disease in endemic areas. However, one question that remains to be answered is whether similar results will occur in areas with different schistosomiasis prevalences $(5 \%, 10 \%$, or $40 \%)$.

\section{ACKNOWLEDGMENTS}

We are indebted to Drs. Izabela Voieta and Juliana Papatella for their help during the fieldwork. We also thank Mrs. Silvana Romano for organizing the blood bank. We acknowledge the contribution of the Secretary of Health of Teófilo Otoni for the support and assistance provided during the study in Topázio.

\section{FINANCIAL SUPPORT}

This investigation was partially supported by Fundação de Amparo à Pesquisa do Estado de Minas Gerais (FAPEMIG) and Conselho Nacional de Desenvolvimento Cientifico e Tecnológico $(\mathrm{CNPq}) /$ Brazil. 


\section{CONFLICT OF INTEREST}

The authors declare that there is no conflict of interest.

\section{REFERENCES}

1. Ministério da Saúde. Secretaria de Vigilância em Saúde. Situação epidemiológica da Esquistossomose no Brasil. Grupo Técnico das Parasitárias, Sub HA/CGDT/DEVEP/SVS/MS Brasília: Ministério da Saúde; 2010. [Cited 2013 June]. Available at: http://portal.saude.gov.br/ portal/arquivos/pdf/situacao_esquistossomose_brasil_abril2011.pdf.

2. Lambertucci JR, Cota GF, Pinto-Silva RA, Serufo JC, Gerspacher-Lara R, Drummond SC, et al. Hepatosplenic schistosomiasis in field-based studies: a combined clinical and sonographic definition. Mem Inst Oswaldo Cruz 2001; 96:S147-S150.

3. Lambertucci JR, Serufo JC, Gerspacher-Lara R, Rayes AA, Teixeira R, Nobre V, et al. Schistosoma mansoni: assessment of morbidity before and after control. Acta Trop 2000; 77:101-109.

4. Voieta I, Queiroz LC, Andrade LM, Silva LC, Fontes VF, Barbosa Jr A, et al. Imaging techniques and histology in the evaluation of liver fibrosis in hepatosplenic schistosomiasis mansoni in Brazil: a comparative study. Mem Inst Oswaldo Cruz 2010; 105:414-421.

5. Lambertucci JR, Silva LC, Andrade LM, Queiroz LC, Carvalho VT, Voieta I, et al. Imaging techniques in the evaluation of morbidity in schistosomiasis mansoni. Acta Trop 2008; 108:209-217.

6. Homeida M, Abdel-Gadir AF, Cheever AW, Bennett JL, Arbab BM, Ibrahium SZ, et al. Diagnosis of pathologically confirmed Symmers' periportal fibrosis by ultrasonography: a prospective blinded study. Am J Trop Med Hyg 1988; 38:86-91.

7. Homeida M, Ahmed S, Dafalla A, Suliman S, Eltom I, Nash T, et al. Morbidity associated with Schistosoma mansoni infection as determined by ultrasound: a study in Gezira, Sudan. Am J Trop Med Hyg 1988; 39:196-201.

8. Hatz CF. The use of ultrasound in schistosomiasis. Adv Parasitol 2001; 48:225-284

9. Petroianu A, Oliveira AE, Alberti LR. Hypersplenism in schistosomotic portal hypertension. Arch Med Res 2005; 36:496-501.

10. Lambertucci JR. Schistosoma mansoni: pathological and clinical aspects. In: Jordan P, Webbe G, editors. Human Schistosomiasis. $3^{\text {rd }}$ ed. Wallingford: Cab International; 1993. p. 195-235.

11. Souza MR, Toledo CF, Borges DR. Thrombocytemia as a predictor of portal hypertension in schistosomiasis. Dig Dis Sci 2000; 45:1964-1970.

12. Lambertucci JR, Silva LC, Antunes CM. Aspartate aminotransferase to platelet ratio index and blood platelet count are good markers for fibrosis evaluation in schistosomiasis mansoni. Rev Soc Bras Med Trop 2007; 40:599.

13. Lambertucci JR, Gerspacher-Lara R, Pinto-Silva RA, Barbosa MM, Teixeira R, Barbosa HF, et al. The Queixadinha project: morbidity and control of schistosomiasis in an endemic area of the northeast of Minas Gerais, Brazil. Rev Soc Bras Med Trop 1996; 29:127-135.

14. Kloetzel K. Splenomegaly in schistosomiasis mansoni. Am J Trop Med Hyg 1962; 11:472-476.

15. Prata A. Influence of the host related factors in the development of the hepatosplenic form of schistosomiasis mansoni. Mem Inst Oswaldo Cruz 1992; 87 (supl IV):39-44.
16. Lambertucci JR, Rocha RS, Carvalho S, Katz N. Schistosomiasis mansoni in Minas Gerais. Rev Soc Bras Med Trop 1987; 20:47-52.

17. Gerspacher-Lara R, Pinto-Silva RA, Serufo JC, Rayes AA, Drummond SC, Lambertucci JR. Splenic palpation for the evaluation of morbidity due to schistosomiasis mansoni. Mem Inst Oswaldo Cruz 1998; 93 (supl I):245-248.

18. Prata A, Ruiz-Guevara R, Antunes CM, Marinho CC, Queiroz LC, Voieta I, et al. Comparison between clinical and ultrasonographic findings in cases of periportal fibrosis in an endemic area for schistosomiasis mansoni in Brazil. Rev Soc Bras Med Trop 2010; 43:129-134.

19. Drummond SC, Pereira SR, Silva LC, Antunes CM, Lambertucci JR. Schistosomiasis control program in the state of Minas Gerais in Brazil. Mem Inst Oswaldo Cruz 2010; 105:519-523.

20. Richter J, Domingues AL, Barata CH, Prata AR, Lambertucci JR. Report of the second satellite symposium on ultrasound in schistosomiasis. Mem Inst Oswaldo Cruz 2001; 96:S151-S156.

21. Rosenberg HK, Markowitz RI, Dolberg H, Park C, Hubbard A, Bellah RD. Normal splenic size in infants and children: sonografic measurements. AJR 1991; 157:119-121.

22. Andrade ZA. Schistosomal hepatopathy. Mem Inst Oswaldo Cruz 2004; 99 (supl 1):51-57.

23. Lambertucci JR, Voieta I, Resende V. Mild, moderate and intense Symmers's fibrosis in hepatosplenic schistosomiasis mansoni. Rev Soc Bras Med Trop 2009; 42:611-612.

24. Lambertucci JR, Silva RA, Gerspacher-Lara R, Barata CH. Acute Manson's schistosomiasis: sonographic features. Trans R Soc Trop Med Hyg 1994; 88:76-77.

25. Lambertucci JR, Silva LC, Andrade LM, Queiroz LC, Pinto-Silva RA. Magnetic resonance imaging and ultrasound in hepatosplenic schistosomiasis mansoni. Rev Soc Bras Med Trop 2004; 37:333-337.

26. Lambertucci JR. Acute schistosomiasis mansoni: revisited and reconsidered. Mem Inst Oswaldo Cruz 2010; 105:422-435.

27. Queiroz LC, Drummond SC, Matos ML, Paiva MB, Batista TS, Kansaon AZ, et al. Comparative randomised trial of high and conventional doses of praziquantel in the treatment of schistosomiasis mansoni. Mem Inst Oswaldo Cruz 2010; 105:445-448.

28. Prata A, Andrade Z. Liver fibrosis without splenomegaly. O Hospital $1963 ; 63: 617-623$.

29. Al-Mofarreh M, Al-Moagel-Alfarag M, Ashoor T, Shadoochy F, Duodenal varices. Report of 13 cases. Z Gastroenterol 1986; 24:673-680.

30. Bommana V, Shah P, Kometa M, Narwal R, Sharma P. A case of isolated duodenal varices secondary to chronic pancreatitis with review of literature. Gastroenterol Res 2010; 3:281-286.

31. Lambertucci JR, Duani H, Prata PH, Voieta I. Pseudothrombocytopenia in schistosomiasis mansoni. Rev Soc Bras Med Trop 2011; 44:792.

32. Lippi G, Plebani M. EDTA-dependent pseudothrombocytopenia: further insights and recommendations for prevention of a clinically threatening artifact. Clin Chem Lab Med 2012; 50:1281-1285.

33. Sinha SK, Mandal PK, Mallick J. Pseudothrombocytopenia -- a caveat. J Indian Med Assoc 2011; 109:476-478.

34. Chia J, Hsia CC. Pseudothrombocytopenia. Blood 2011; 117:4168.

35. Dusse LMS, Vieira LM, Carvalho MG. Thrombocytopenia. J Bras Patol Med Lab 2004; 40:321-324.

36. Cohen AM, Cycowitz Z, Mittelman M, Lewinski UH, Gardyn J. The incidence of pseudothrombocytopenia in automatic blood analyzers. Haematologia (Budap) 2000; 30:117-121. 